\title{
PRESERVAÇÃO DA ÁREA CÁRSTICA DE LAGOA SANTA - MG, ATRAVÉS DA EDUCAÇÃO AMBIENTAL
}

\author{
José Antônio Souza de Deus(*), Claiston Cosme Damião Ferreira(**) \& \\ Ronan Silva Rodrigues(***)
}

\begin{abstract}
RESUMO
A peculiaridade do patrimônio cárstico da região de Lagoa Santa é reconhecida internacionalmente, bem como seus sítios espeleológicos e locais historicamente relevantes, com seu potencial turístico intrínseco. É necessária portanto sua preservação, buscando uma relação de custo-benefício positiva para a comunidade local. Esse ecossistema cárstico é altamente vulnerável a depredações de carater por vezes irreversível. Neste sentido, vimos a necessidade da produção de materiais educativo-ambientais: o protótipo de um "software" destinado essencialmente às escolas, e três protótipos de "folders", destinados à população local, turistas e empresários. Havendo interesse de instituições públicas ou privadas em patrocinar este material educativo-ambiental, ele poderá ser reproduzido e distribuído para a sociedade envolvente.

Acreditamos que, a ação conjunta de todos os segmentos sociais, será capaz de garantir a preservação desse patrimônio cárstico e promover o desenvolvimento econômico regional, de forma sustentável.
\end{abstract}

\section{INTRODUÇÃO}

Após a conferência de Estocolmo em 1972, as preocupações com as questões ambientais se intensificaram em escala mundial. No Brasil, diversas iniciativas de preservação ambiental vem sendo inclusive implementadas nos últimos anos, como a criação em 1990, pelo Governo federal, da APA (Área de Proteção Ambiental) Carste, na região de Lagoa Santa, na porção central do Estado de Minas Gerais, no limite norte da Região Metropolitana de Belo Horizonte $(\mathrm{RMBH})$. A área é ainda susceptível entretanto às conseqüências advindas da expansão urbana.

A APA Carste de Lagoa Santa foi criada com o objetivo de garantir uma relação harmônica entre as intervenções antrópicas e a preservação do patrimônio cárstico regional. As APAs correspondem à unidades de conservação, em que não há uma intervenção direta do Poder Público nas porções territoriais por elas compreendidas, nem qualquer tipo de limitação direta (desapropriação) no direito de propriedade, assegurado constitucionalmente (FUNDAÇÃO BIODIVERSITAS, 1996). No entanto, para impedir que se desenvolvam quaisquer ações potencialmente lesivas ao meio ambiente no interior de uma APA, é necessária uma avaliação prévia (gerenciamento) por parte dos órgãos ambientais competentes, de qualquer atividade econômica a ser implantada na área.

$\mathrm{Na}$ região cárstica de Lagoa Santa (mesmo no interior da unidade de conservação legalmente protegida), ainda são desenvolvidas atividades econômicas nocivas ao meio ambiente ameaçando consequentemente, parte significativa do patrimônio histórico-cultural regional e a qualidade de vida de expressiva parcela da sociedade envolvente
(FUNDAÇÃO BIODIVERSITAS, 1996).

Para que as populações direta (moradores e empresários) ou indiretamente (turistas em geral) envolvidas possam se conscientizar a respeito da relevância da preservação da região, é imprescindível um conhecimento preciso das características geológicogeomorgológicas que deram origem aos sítios espeleológicos, arqueológicos e paleontológicos, de grande valor científico e cultural, e que possuem extraordinária beleza cênica. Na realidade, só se ama aquilo que se conhece (SAINT-EXUPERY, 1983). E neste sentido, a educação desempenha uma função determinante. Vale assinalar a advertência feita pelo oceanógrafo Jacques Cousteau1: "Já faz algumas décadas que sabemos quais são os principais tipos de agressões ecológicas que ameaçam o planeta; mas isso não é suficiente, falta educar e desenvolver a consciência das pessoas para mudar o quadro calamitoso desta situação".

\section{Localização da área de estudo:}

No que se refere aos registros científicos, é antiga a literatura existente sobre a região de Lagoa Santa. Já no século XIX, o naturalista dinamarquês Peter Lund, e outros naturalistas europeus, desenvolveram diversos trabalhos na região, particularmente no campo da Paleontologia e da Botânica. No contexto da Educação Ambiental, a bibliografia disponível ainda é restrita. Destacam-se neste particular os trabalhos de KOHLER (1989; 1994); a obra de CARTELLE (1994) - que enfatiza a importância da preservação do patrimônio cárstico regional; bem como os trabalhos publicados pela FUNDAÇÃO BIODIVERSITAS (1996). Ainda existem entretanto lacunas, na bibliografia científica relacionada com a temática ambiental, 
na região em foco.

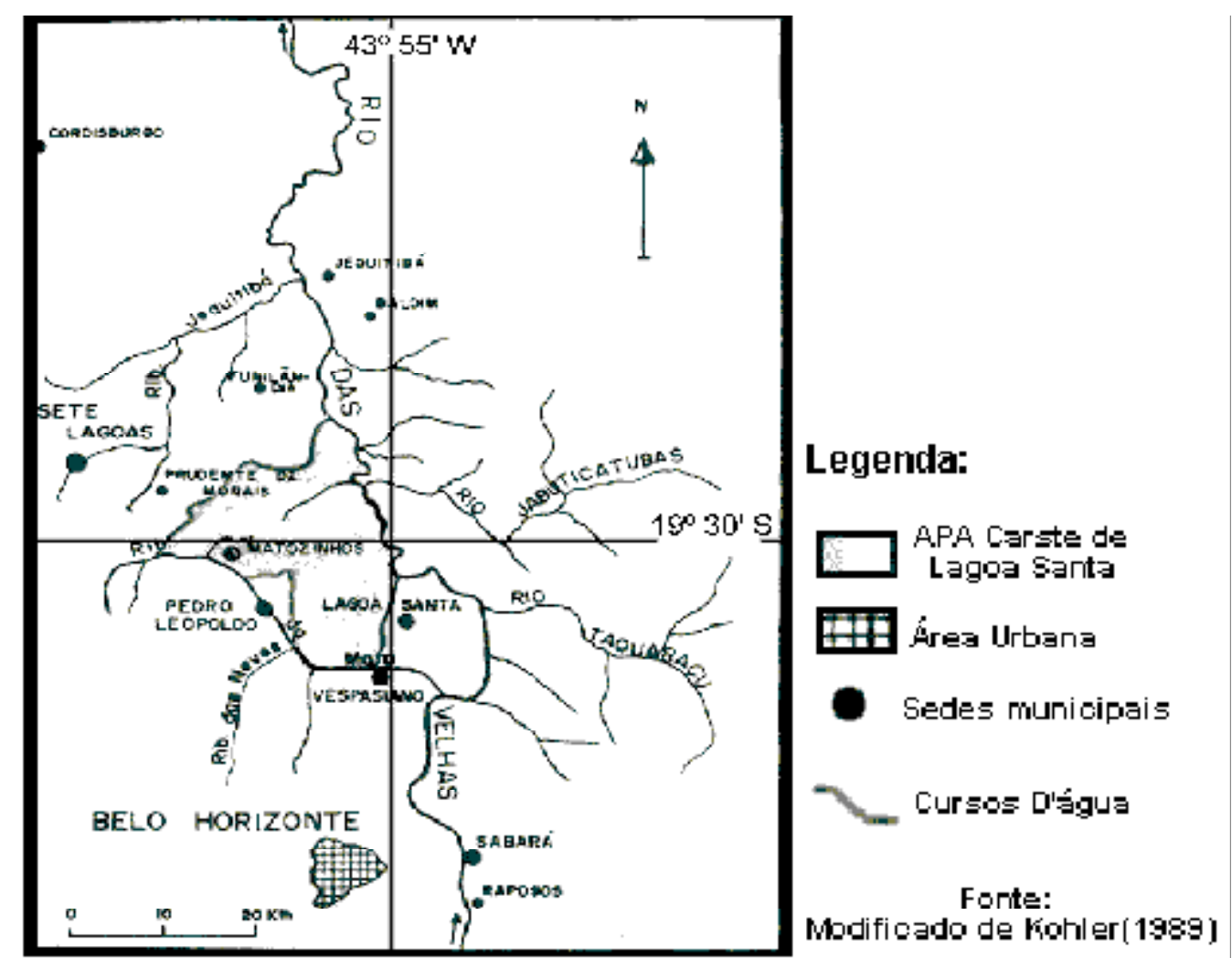

\section{OS ECOSSISTEMAS REGIONAIS}

A região de Lagoa Santa é um ecossistema cárstico altamente vulnerável a degradação ambiental, devido, essencialmente, às características específicas de seus diversos sítios. Uma parte desse ecossistema, ainda mais frágil, são os aqüíferos nele encontrados, devido a sua relação hidrodinâmica com a superfície. Uma vez que estes aqüíferos viessem a ser poluídos, os impactos ambientais seriam irreversíveis e ocorreriam em grande escala, pois, segundo KOHLER (1989), o endocarste funciona como grande armazenador de águas que, devido a macroporosidade de suas rochas, bem como a existência de filtro natural (cobertura pedológica), são extremamente susceptíveis a serem poluídos nos afloramentos. Daí a necessidade de uma conscientização efetiva da população local (com a formação de agentes multiplicadores), visitantes e empresários, quanto à singularidade da hidrologia cárstica de Lagoa Santa. De acordo com KOHLER (1994: 328),

“... os compartimentos mais elevados funcionam como zona de recarga, enquanto os compartimentos basais constituem a zona de descarga do aqüífero. Toda dinâmica processa-se entre esses dois extremos. Na região de Lagoa Santa, a sede municipal de Matozinhos situa-se na área do aqüífero cárstico. Isso requer estudos específicos de saneamento, e os deflúvios da cidade devem ser desviados do manancial de recarga para não poluir os compartimentos mais baixos, situados na zona de descarga." (KOHLER, 1994: 328)

Verifica-se que, ao longo dos últimos anos, houve inúmeras agressões ao ecossistema regional (naturalmente frágil). Essas agressões têm causas diversas: atuação da atividade mineradora e das indústrias (bases da economia regional), expansão urbana, ocupação desordenada do solo, bem como seu uso indevido pela atividade agropecuária. A desinformação de algumas pessoas já contribuiu significativamente para a danificação de parte considerável deste patrimônio cárstico.

Um exemplo de depredação ocorrida nos últimos anos, foi a destruição, pela atividade mineradora, da Lapa Vermelha (situada próxima a cidade de Lagoa Santa), local onde Lund encontrou o primeiro fóssil humano da América do Sul, com idade entre 10 e 12 mil anos (ou mais), e que mais tarde se popularizou com o nome de Homem de Lagoa Santa (CARTELLE, 1994). Na realidade, “... esse marco histórico desapareceu para sempre, destruído pela mineração de calcário utilizado na indústria cimenteira. Um santuário da história nacional está em qualquer lugar, fazendo parte de um prédio ou de uma ponte..." (CARTELLE, 1994: 117). 
Recentemente, ocorreu a destruição, também pela atividade mineradora, de um arco calcário no município de Matozinhos, no qual havia inscrições rupestres, de grande valor arqueológico. De acordo com arqueólogos nestes casos as multas aplicadas nada significam, em comparação ao dano causado. Uma questão bastante complexa neste sentido corresponderia ainda à dificuldade de se avaliar os custos do impacto de explosões realizadas, por exemplo, para a exploração de calcário (e dolomito) em sítios de mineração muito próximos a monumentos arqueológicos e espeleológicos (DEUS, 1986).

Naturalmente, não é necessário se desacelarar o desenvolvimento econômico para se preservar o ecossistema cárstico de Lagoa Santa. Mas é indispensável a realização de estudos prévios em locais onde estejam, por exemplo, planejadas a instalação de plantas industriais, para se evitar destruições, às vezes irreversíveis, como já assinalamos.

Embora possam ser iniciativas relativamente onerosas às indústrias, além da elaboração de Relatórios de Impactos Ambientais (RIMAs), podem ser adotadas medidas que utilizem tecnologias adequadas para evitar a disseminação de efluentes na atmosfera, cursos d'água e aqüíferos; medidas úteis para as próprias empresas, especialmente com o advento da ISO 14.000. Cuidados devem ser tomadas evidentemente, também pelo poder público, em relação ao destino dos esgotos oriundos de áreas urbanas.

Em relação à cobertura vegetal da região de Lagoa Santa, se compararmos a vegetação atual com a do século passado, verifica-se que essa região passou por profundas transformações em decorrência da ação antrópica, acentuada principalmente pela sua posição geográfica (proximidade de centros urbanos). Na realidade, essa vegetação, em termos relativos, quase se extinguiu, como bem ressaltou KOHLER (1989: 21):

"As matas eram encontradas, antes da depredação pelo homem, ao longo dos córregos $e$ rios (matas galeria) e, sobretudo, na região cárstica. Os campos cerrados cobriam as superfícies aplainadas e os solos menos férteis que cobriam os filitos. Ao longo das várzeas desenvolvia-se a vegetação dos brejos e, nos lagos, instalavam-se plantas aquáticas. Hoje restam os cerrados e as matas semidessiduais sobre os afloramentos de calcário não explorados ou cultivados e, mesmo esses, mostram-se espoliados de suas espécies nobres." (KOHLER, 1989: 21).

No que concerne aos ecossistemas ${ }^{2}$ dessa região cárstica, procuramos identificar alguns exemplos ilustrando diferentes condições ou estágios de preservação e/ou degradação, que julgamos representativos, de acordo com parâmetros de classificação de ecossistemas adotados pela UICNPNUMA-WWF (1991: 35), e compreendendo:

- Sistemas naturais: "Ecossistemas onde, desde a Revolução Industrial (em torno de 1750), o impacto humano não seja maior do que aquele de qualquer outra espécie nativa, e não tenha afetado a estrutura do ecossistema. Nesta concepção o impacto humano exclui mudanças de alcance mundial, tais como a mudança climática devido ao aquecimento mundial." Exemplo: Gruta Poções, localizada no município de Matozinhos (que se encontra praticamente inexplorada/Foto 1).

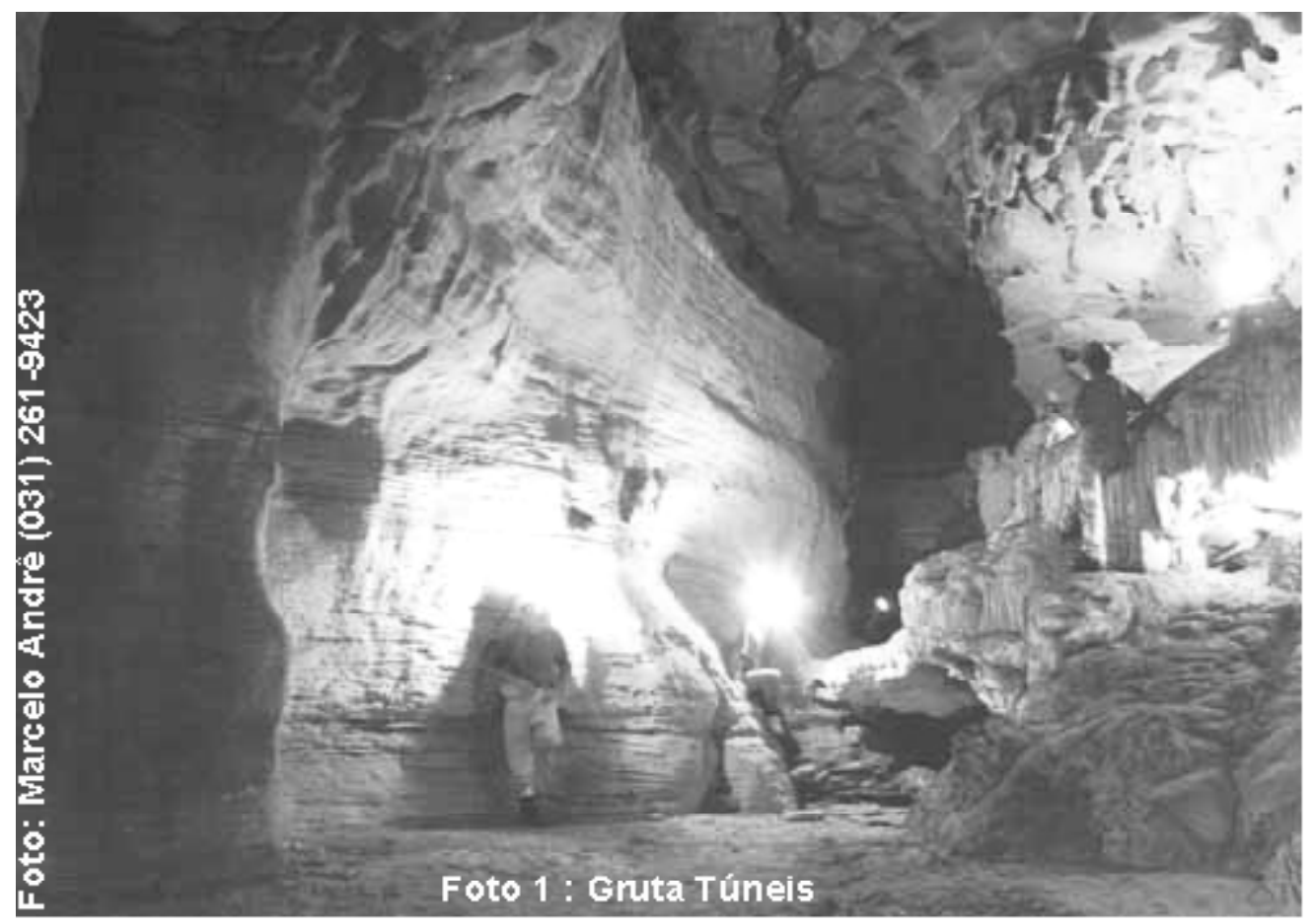


- Sistemas modificados: "Ecossistemas onde o impacto humano é maior do que aquele de qualquer outra espécie, mas cujos componentes estruturais não são cultivados". Por exemplo: a Gruta da Lapinha, que teve a área próxima de sua entrada bastante modificada, e é hoje uma das principais atrações turísticas da região (Foto 2).

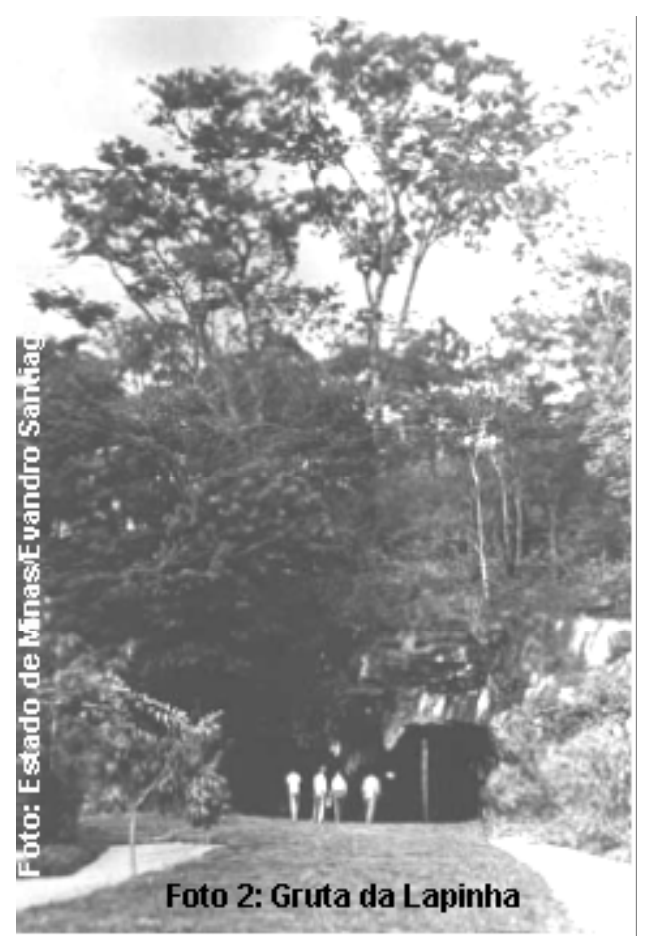

Sistemas Cultivados: "Ecossistemas onde o impacto humano é maior do que aquele de qualquer outra espécie, e em que a maioria dos componentes estruturais são cultivados". Por exemplo: A cultura de hortaliças no município de Pedro Leopoldo (Foto 3).

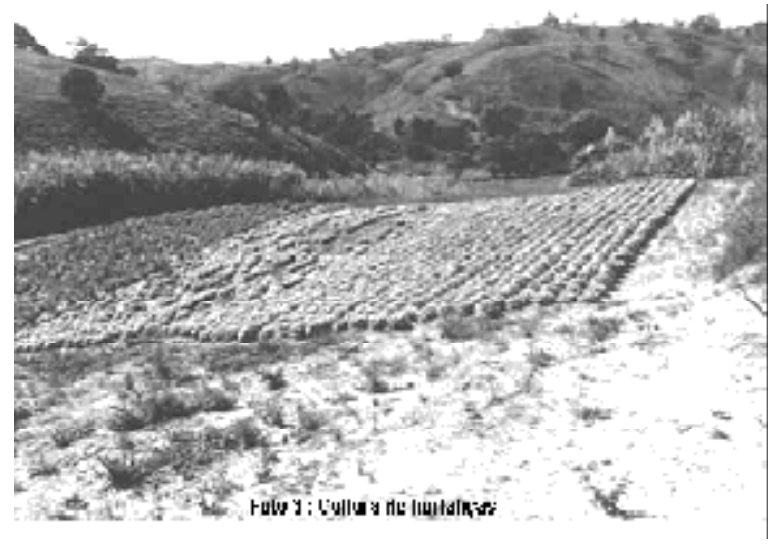

- Sistemas construídos: "Ecossistemas dominados por edificações, estradas, aeroportos, portos, barragens, minas e outras construções antrópicas. Inclui parques, jardins e campos de golfe urbanos e suburbanos". Por exemplo: o Aeroporto Internacional Presidente Tancredo Neves, construído em plena área cárstica, no município de Confins (Foto 4).

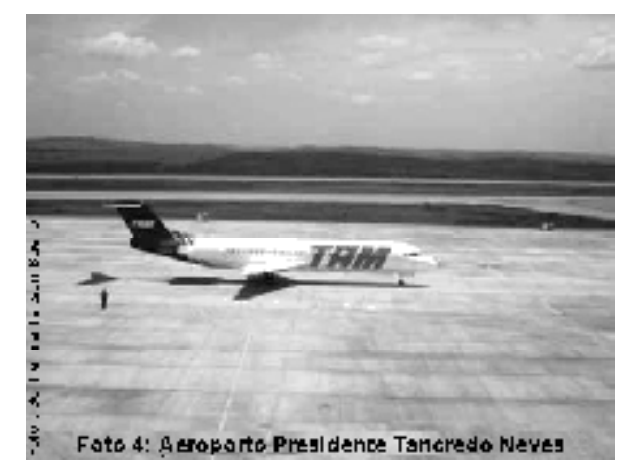

- Sistemas degradados: "Ecossistemas cuja diversidade e produtividade tenham sido tão reduzidas, que será improvável conseguir sua restituição sem a adoção de medidas como reabilitação ou recuperação". Por exemplo: a lagoa que deu origem à própria denominação da cidade de Lagoa Santa, e que atualmente encontra-se bastante assoreada e poluída (Foto $5)$.

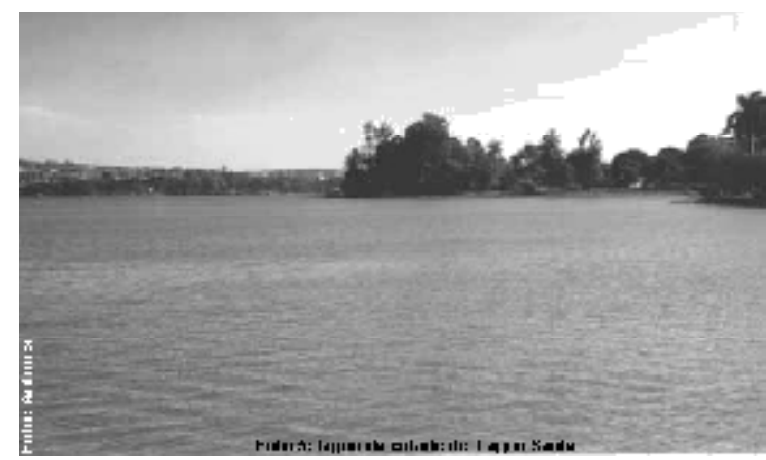

\section{A UTILIZAÇÃO DE “SOFTWARE” E "FOLDERS" NA PERSPECTIVA DA EDUCAÇÃO AMBIENTAL}

Para a efetivação deste trabalho foi realizado um levantamento bibliográfico e cartográfico da região cárstica de Lagoa Santa, acompanhado de participação direta em trabalhos de Educação Ambiental, promovidos pelo IBAMA / MG, e executados pela PLANAVE S/A Estudos e Projetos de Engenharia (e direcionados, principalmente, à formação de agentes multiplicadores aptos a auxiliar as prefeituras e órgãos ambientais que atuem na área, na 
preservação dos sítios cárstico-espeleológicos, arqueológicos, paleontológicos, faunísticos e florísticos regionais). Foram também realizados trabalhos de campo na região, com o objetivo de interagir com a população local, e investigar melhor a área de estudo.

O "software" proposto foi confeccionado a partir do programa Apple Media Tool, e permite que, através de comandos simples e interativos, o usuário, mesmo com escasso conhecimento em informática, tenha oportunidade de navegar por imagens, fotos e textos relacionados com os temas abordados. A utilização deste "software" é realmente bastante simples. Naturalmente é necessário que os usuários (especialmente alunos) tenham acesso (nas escolas) a um computador com sistema de multimídia, placa de som e monitor "super VGA". Sendo assim, basta acessar o disco de CD-ROM e aguardar alguns segundos, para que o usuário tenha acesso aos textos, figuras e fotos referentes à área cárstica de Lagoa Santa.

Quanto aos três protótipos de "folders" elaborados, cada modelo foi confeccionado tendo em perspectiva um público específico: população local, turistas e empresários. Nestes protótipos, há temas comuns: mapas da região cárstica de Lagoa Santa, breve histórico da região e uma foto mostrando com bastante nitidez o processo de formação de uma estalactite no interior de uma gruta calcária (Foto 6). Mas, evidentemente se adotaram abordagens específicas, em cada protótipo de "folder", de acordo com o público alvo.

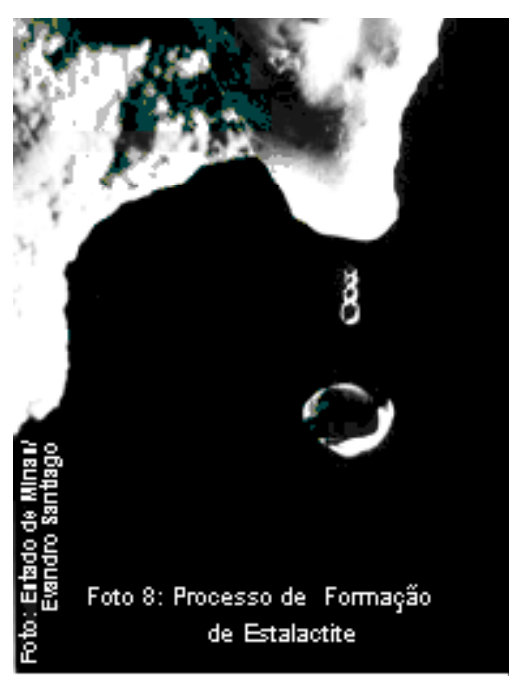

No "folder" direcionado à população local, foi focalizada a importância da comunidade conhecer intimamente sua própria região e articular-se às prefeituras e órgãos ambientais, que atuem na região. Enfatizamos aí que a questão ambiental não será solucionada por meio de atuações isoladas seja de prefeituras, de órgãos ambientais ou da comunidade local; e que somente ações conjuntas poderão romper obstáculos estruturais inerentes à realidade social do país como pobreza, despreparo cultural e carência educacional das massas.

Em relação ao "folder" turístico, apresentamos os principais focos de interesse turístico da região como belíssimas grutas (com imensa diversidade de espeleotemas, inscrições rupestres, aprazíveis paisagens), e os marcos históricos que proporcionam ao turista a oportunidade de uma incursão (e reflexão) sobre o nosso passado. A região efetivamente constitui um singular patrimônio cárstico, dotado de incrível beleza cênica, internacionalmente reconhecido.

No terceiro protótipo de "folder", destinado aos empresários da região (e a outros que eventualmente pretendam ali investir) assinalamos o imenso potencial da área para o ecoturismo. Com tantas riquezas naturais e marcos históricos de valor inestimável, a região ainda se encontra parcialmente localizada nos limites da RMBH (estando situada portanto próximo de um grande mercado consumidor) e está conectada ao restante do mundo através do Aeroporto Internacional Presidente Tancredo Neves. Haveria naturalmente um ingresso de divisas na região, decorrente do desenvolvimento da indústria do turismo (em ascensão não somente no Brasil, mas em todo o mundo).

A criação da APA Carste, na região de Lagoa Santa, serve de exemplo de que nos últimos anos está havendo maior preocupação com as questões ambientais no Brasil, em decorrência das inúmeras degradações, que têm atingido de forma bastante negativa as comunidades. Como salientou o célebre chefe indígena Seatle, na antológica carta-resposta por ele enviada ao presidente dos Estado Unidos, em 1954 (e citada, ou divulgada por diferentes organismos e estudiosos): “... O homem não tramou o tecido da vida; ele é simplesmente um de seus fios. Tudo o que fizer ao tecido, fará a si mesmo".

Acreditamos que, a partir do momento que a sociedade envolvente passar a conhecer intimamente sua região, haverá inúmeras discussões entre os diversos segmentos da comunidade, o que poderá culminar em atitudes práticas em busca de um convívio harmônico entre preservação do patrimônio natural e atividades econômicas ali desenvolvidas.

\section{AGRADECIMENTOS}

Os autores agradecem ao Instituto de Geociências da Universidade Federal de Minas Gerais (IGC/UFMG), ao Instituto Brasileiro do Meio Ambiente e dos Recursos Naturais Renováveis (IBAMA-MG), e a PLANAVE Estudos e Projetos de Engenharia. Agradecemos, também, àquelas pessoas que contribuíram direta ou indiretamente para a realização deste trabalho: Adriano Maurício Cruz, Cláudio Batista Vieira, Guilherme Taitson Bueno, Jhoerbesson Lopes Silva Monteiro, Marcelo Andrê, Marta Bouissou Morais, Rosângela Albano Silva, dentre outros; e por fim, a todos os colegas do Curso de Multiplicadores de Educação Ambiental, realizado na região de Lagoa Santa (Pedro Leopoldo), no segundo semestre de 1997. 


\section{REFERÊNCIAS BIBLIOGRÁFICAS}

CARTELlE, C. Tempo Passado; Mamíferos do Pleistoceno em Minas Gerais. Belo Horizonte: Editora Palco, 1994. 132p.

DEUS, J. A. S. Os Impactos Sócio-Ambientais da Mineração e a Resistência Cultural e Territorial das Nações Indígenas. Rio de Janeiro: Instituto Geociências da UFRJ, 1986. 170p. (Dissertação, Mestrado).

FUNDAÇÃO BIODIVERSITAS. Plano de Gestão; Área de Proteção Ambiental Carste de Lagoa Santa - MG. Belo Horizonte, 1996. 41p.
GOLDFEDER. S.A Supercaravela de Cousteau. Globo Ciência, Rio de Janeiro, $62: 22-29,1996$.

KOHLER, H. C. Geomorfologia Cárstica na Região de Lagoa Santa - MG. São Paulo: Faculdade de Filosofia, Letras e Ciências Humanas da USP, 1989. 113p. (Tese, Doutorado).

KOHLER, H. C. Geomorfologia Cárstica. In: GUERRA, A. J. T., CUNHA, S. B. Geomorfologia; Uma atualização de Bases e Conceitos. Rio de Janeiro: Bertrand Brasil, 1994 p. 309 - 334.

SAINT-EXUPERY, A. O Pequeno Príncipe 26Ed. Rio de Janeiro: Agir, 1983.95p.

UICN-PNUMA-WWF. Cuidando do Planeta Terra; Uma Estratégia para o Futuro da Vida. São Paulo: CL-A Cultural Ltda, 1991. $250 \mathrm{p}$.

${ }^{2}$ Neste trabalho, adotou-se o conceito de ecossistema como sendo "um sistema de plantas, animais e outros organismos em conjunto com os componentes nãovivos." (UICN-PNUMA-WWF, 1991:35).

${ }^{1}$ Apud: GOLDFEDER (1996) 